\title{
Effect of Glutamine-Enriched, Elemental Diet on Regeneration of Residual Small Bowel Mucosa and Hepatic Steatosis Following Massive Bowel Resection
}

\author{
Masao Yagi, * Kohya SaKamoto, Tetsuya Inoue, Wataru FuKushima, \\ Tetsuo Hashimoto, Kouichi SHIMIzU, Ryohei IzUMI, \\ and Itsuo MIYAZAKI \\ Department of Surgery II, School of Medicine, Kanazawa University, \\ Kanazawa 920, Japan
}

(Received June 11, 1993)

\begin{abstract}
Summary The effect of an orally administered, glutamine-enriched, elemental diet on the regeneration of small bowel mucosa and hepatic steatosis following massive small bowel resection was examined by determination of the levels of the bromodeoxyuridine labelling indices, alkaline phosphatase activity in the residual jejunal mucosa, and histological change of the liver. The serum glutamine level was significantly higher in the glutamine-enriched diet group than in the glutamine-free diet group, as were the alkaline phosphatase activity in the homogenate of the residual jejunal mucosa and the bromodeoxyuridine labelling index in the residual jejunal mucosa. The histological findings showed that the fat infiltration in the liver was more severe in the glutamine-free diet group than in the glutamine-enriched diet group. These findings suggest that an orally administered, glutamine-enriched, elemental diet promotes the regeneration of the intestinal mucosa and prevents the liver from fat infiltration following a massive small bowel resection.
\end{abstract}

Key Words: massive small bowel resection, glutamine, elemental diet, small bowel mucosa, hepatic steatosis

Massive small bowel resection causes malabsorption due to insufficient length of the small bowel, which disorder can be improved by the adaptation of the intestinal tract. After a massive small bowel resection, the remaining gut begins to adapt through lengthening of villi, thickening of the wall, dilatation, and a

${ }^{*}$ To whom correspondence should be addressed. 
slowing of motility. As a result, diarrhea and steatorrhea are reduced, and absorption of nutrients is improved [1]. Appropriate nutrition is required for supplying the substrates to change the small bowel mucosa during this period of adaptation. Glutamine is an important respiratory substrate for enterocytes [2], and improves intestinal morphology and function in 5-fluorouracil-induced enterocolitis [3]. Glutamine deficiency is associated with gut mucosal atrophy [4]. Addition of glutamine to standard intravenous nutrition attenuates intestinal atrophy [5], and has trophic effects on the pancreas and protective effects against hepatic steatosis [6].

This study was undertaken to determine whether the addition of glutamine to an elemental diet would accelerate the adaptation of the small bowel mucosa and attenuate the development of hepatic steatosis following small bowel resection.

\section{MATERIALS AND METHODS}

Ten male Wistar rats $(210 \pm 25 \mathrm{~g})$ were anesthetized by intraperitoneal administration of pentobarbital $(45 \mathrm{mg} / \mathrm{kg})$. The abdomen was opened and about $80 \%$ mid jejunoileal intestinal resection was performed by transection of the small bowel $5 \mathrm{~cm}$ distal to the ligament of Treitz and $5 \mathrm{~cm}$ proximal to the ileocecal junction. Bowel continuity was reestablished by end-to-end anastomosis. After the operation, the animals were randomized to receive an oral elemental enteral nutrient solution without glutamine (Ajinomoto, Tokyo [7]) or a glutamineenriched diet solution (Ajinomoto). The glutamine-free diet contained 14,012 $\mathrm{mg}$ of amino acids and $79.37 \mathrm{~g}$ of dextrose per $100 \mathrm{~g}$ diet, and appropriate concentrations of electrolytes, vitamins, and minerals. The glutamine-enriched diet contained $21,512 \mathrm{mg}$ of amino acids, 7,500 $\mathrm{mg}$ of glutamine, and $79.37 \mathrm{~g}$ of dextrose per $100 \mathrm{~g}$ diet, and the same concentrations of electrolytes, vitamins, and minerals as the glutamine-free diet (Table 1). The nutrient solutions were prepared as $1 \mathrm{kcal} /$ $\mathrm{ml}$ in tinted bottles. The animals were allowed to drink the nutrient solution from the bottle ad libitum. All animals were given free access to tap water during the first $10 \mathrm{~h}$ following the operation and to one of the two nutrient solutions from the first postoperative day until the end of the study.

Animals were weighed and the daily feeding volume measured on every postoperative day. On the seventh day of feeding, animals were anesthetized $2 \mathrm{~h}$ after an intraperitoneal injection of $20 \mathrm{mg} / \mathrm{kg}$ of bromodeoxyuridine (BrdUrd), and blood was drawn from the left ventricle into a heparinized syringe for the measurement of plasma glutamine, alanine, and glutamic acid levels, which were determined by high-performance liquid chromatography [8]. Immediately following exsanguination, the liver and residual jejunum were rapidly excised. The jejunum was divided into two segments. The mucosa was scraped with a slide glass from $2 \mathrm{~cm}$ of jejunum and homogenized in $2.0 \mathrm{ml}$ of saline. The content of protein and the level of alkaline phosphatase (Al-p) activity in the homogenate were then 
Table 1. Components of the glutamine-free and glutamine-enriched elemental diets.

\begin{tabular}{lcc}
\hline Nutrient & $\begin{array}{c}\text { Glutamine-free } \\
\text { elemental diet }\end{array}$ & $\begin{array}{c}\text { Glutamine-enriched } \\
\text { elemental diet }\end{array}$ \\
\hline L-Isoleucine & 803 & 803 \\
L-Leucine & 1,124 & 1,124 \\
L-Lysine & 888 & 888 \\
L-Methionine & 810 & 810 \\
L-Phenylalanine & 1,089 & 1,089 \\
L-Tyrosine & 138 & 138 \\
L-Threonine & 654 & 654 \\
L-Tryptophan & 189 & 189 \\
L-Valine & 876 & 876 \\
L-Arginine & 1,163 & 1,163 \\
L-Histidine & 463 & 463 \\
L-Alanine & 1,124 & 1,124 \\
L-Asparagine & 1,823 & 1,823 \\
L-Glutamine & 0 & 7,500 \\
L-Glycine & 631 & 631 \\
L-Proline & 788 & 788 \\
L-Serine & 1,449 & 1,449 \\
Total amino acid content & 14,012 & 21,512 \\
Dextrose $(\mathrm{g} / 100 \mathrm{~g})$ & 79.37 & 79.37 \\
Calories $(\mathrm{kcal} / 100 \mathrm{~g})$ & 379 & 409 \\
Nitrogen $(\mathrm{g} / 100 \mathrm{~g})$ & 2.04 & 3.48 \\
\hline
\end{tabular}

The contents of the amino acids are expressed as $\mathrm{mg} / 100 \mathrm{~g}$ of elemental diet.

determined $[9,10]$. The activity of Al-p was expressed as international units (IU)/ $\mathrm{mg}$ protein.

A small portion of the liver and a small segment of the jejunum were placed in $10 \%$ buffered formalin and processed for histologic examination. The sections of jejunum were incubated with anti-bromodeoxyuridine monoclonal antibody (Becton Dickinson Monoclonal Center, Mountain View, CA) and then stained by the avidin-biotin-peroxidase complex method [11]. All labeled nuclei were regarded as positive. One thousand epithelial cells of jejunum were counted in each of the 5 to 10 microscopic fields to determine the average BrdUrd labelling index [11].

Data were expressed as means $\pm \mathrm{SD}$, and analyzed by Student's $t$-test. Statistical significance was accepted at the $p<0.05$ level.

\section{RESULTS}

The initial weight of the rats in the glutamine-free diet group was $165 \pm 16 \mathrm{~g}$, and $168 \pm 12 \mathrm{~g}$ in the glutamine-enriched diet group; and the final weight was $182 \pm 44 \mathrm{~g}$ and $186 \pm 32 \mathrm{~g}$, respectively. There were no significant differences between the two groups in terms of initial or final weight. The average diet consumption from the first to third postoperative day was $40 \pm 18 \mathrm{kcal}$ in the glutamine-free 
diet group and $42 \pm 14 \mathrm{kcal}$ in the glutamine-enriched diet group; and that from the fourth to sixth postoperative day was $56 \pm 25 \mathrm{kcal}$ and $60 \pm 21 \mathrm{kcal}$, respectively. Again, there were no significant differences between the two groups (Table 2).

The plasma glutamine and alanine contents in the glutamine-enriched diet group were $573.1 \pm 23.0 \mathrm{nmol} / \mathrm{ml}$ and $394.1 \pm 24.5 \mathrm{nmol} / \mathrm{ml}$, respectively, which were significantly higher than the values of $504.3 \pm 51.3 \mathrm{nmol} / \mathrm{ml}$ and $306.2 \pm 51.8$ $\mathrm{nmol} / \mathrm{ml}$, respectively, in the glutamine-free diet group. The plasma glutamic acid content showed no significant difference between the two groups (Table 3).

The BrdUrd labelling index in the residual jejunal epithelium and Al-p activity in the homogenate of the residual jejunal mucosa were, respectively, $0.32 \pm$

Table 2. Changes in weight and average diet consumption of experimental rats fed a glutamine-free or a glutamine-enriched elemental diet for 7 consecutive days following $80 \%$ resection of the jejunoileum.

\begin{tabular}{lccc}
\hline Weight and diet consumption & $\begin{array}{c}\text { Glutamine-free } \\
\text { elemental diet group }\end{array}$ & $\begin{array}{c}\text { Glutamine-enriched } \\
\text { elemental diet group }\end{array}$ & $p$ \\
\hline Initial weight of rats (g) & $165 \pm 16$ & $168 \pm 12$ & $>0.05$ \\
Final weight of rats (g) & $182 \pm 44$ & $186 \pm 32$ & $>0.05$ \\
Average diet consumption (kcal/day) & & & \\
$\quad$ From 1st to 3rd postoperative day & $40 \pm 18$ & $42 \pm 14$ & $>0.05$ \\
$\quad$ From 4th to 6th postoperative day & $56 \pm 25$ & $60 \pm 21$ & $>0.05$ \\
\hline
\end{tabular}

Values are expressed as mean \pm SD from five rats in each experiment. Initial weight, weight at first postoperative day; Final weight, weight at 7 th postoperative day.

Table 3. Plasma glutamine, alanine, and glutamic acid contents of experimental rats fed a glutamine-free or a glutamine-enriched elemental diet for 7 consecutive days following $80 \%$ resection of the jejunoileum.

\begin{tabular}{lccc}
\hline Amino acid & $\begin{array}{c}\text { Glutamine-free } \\
\text { elemental diet group }\end{array}$ & $\begin{array}{c}\text { Glutamine-enriched } \\
\text { elemental diet group }\end{array}$ & $p$ \\
\hline Glutamine & $504.3 \pm 51.3$ & $573.1 \pm 23.0$ & $<0.05$ \\
Alanine & $306.2 \pm 51.8$ & $394.1 \pm 24.5$ & $<0.05$ \\
Glutamic acid & $123.6 \pm 25.2$ & $103.6 \pm 23.1$ & $>0.05$ \\
\hline
\end{tabular}

Values are expressed as $\mathrm{nmol} / \mathrm{ml}$, mean $\pm \mathrm{SD}$ from five rats in each experiment.

Table 4. Bromodeoxyuridine labelling indices of the residual jejunal epithelium and alkaline phosphatase activity in the homogenate of the residual jejunal mucosa from experimental rats fed a glutamine-free or a glutamine-enriched elemental diet for 7 consecutive days following $80 \%$ resection of the jejunoileum.

\begin{tabular}{lccc}
\hline Indicator of mucosal regeneration & $\begin{array}{c}\text { Glutamine-free } \\
\text { elemental diet group }\end{array}$ & $\begin{array}{c}\text { Glutamine-enriched } \\
\text { elemental diet group }\end{array}$ & $p$ \\
\hline Bromodeoxyuridine labelling index & $0.19 \pm 0.02$ & $0.32 \pm 0.07$ & $<0.01$ \\
Alkaline phosphatase activity & $0.16 \pm 0.03$ & $0.24 \pm 0.04$ & $<0.05$ \\
$\quad$ (International units/mg protein) & & & \\
\hline & &
\end{tabular}



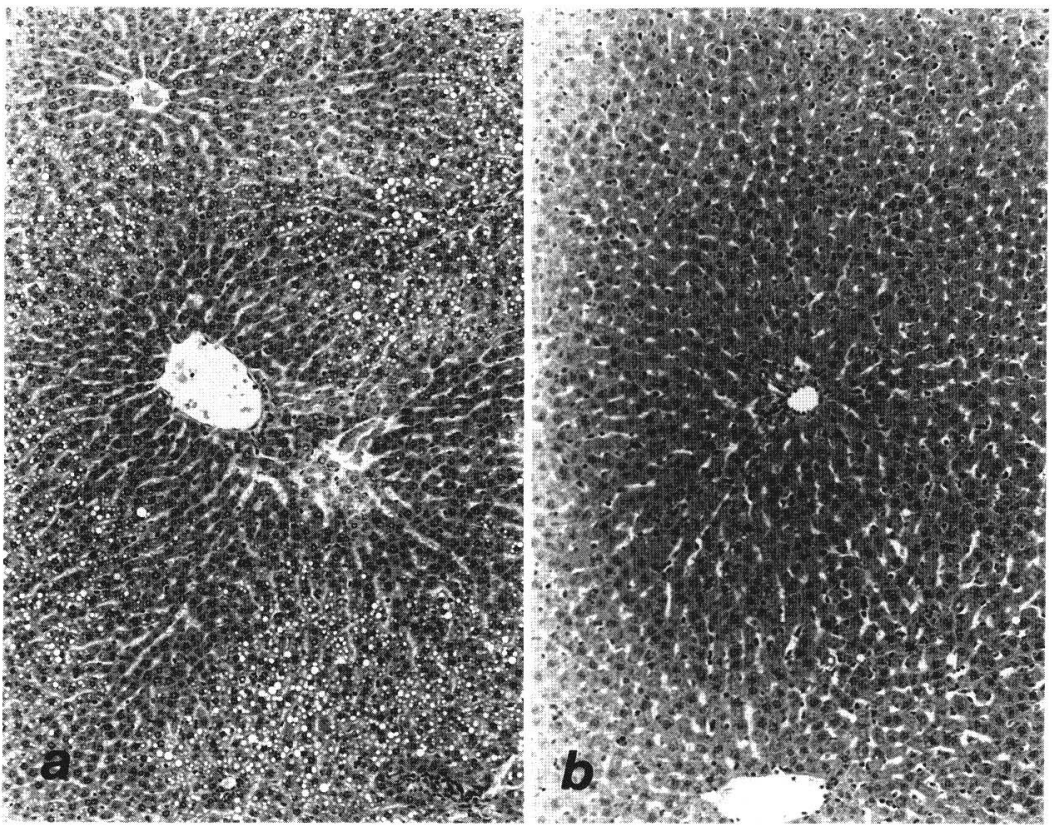

Fig. 1. Histology of the liver $(\times 60)$. (a) Liver from a rat fed a glutamine-free elemental diet for 7 consecutive days following $80 \%$ resection of the jejunoileum. There is extensive fatty vacuolization of hepatocytes predominantly located around the portal area. (b) Liver from a rat fed a glutamine-enriched elemental diet. There is no evidence of fat infiltration in the liver.

0.07 and $0.24 \pm 0.04 \mathrm{IU} / \mathrm{mg}$ protein in the glutamine-enriched group and $0.19 \pm 0.02$ and $0.16 \pm 0.03 \mathrm{IU} / \mathrm{mg}$ protein in the glutamine-free group. The values in the glutamine-enriched diet group were significantly higher than those in the glutamine-free diet group (Table 4).

The histological findings showed that fat infiltration in the liver was more severe in the rats fed the glutamine-free diet than in those given the glutamineenriched one (Fig. 1).

\section{DISCUSSION}

In this study, one group was fed a glutamine-enriched diet, which contained $21,512 \mathrm{mg}$ of amino acids and $409 \mathrm{kcal}$ per $100 \mathrm{~g}$ diet. The other group was fed a glutamine-free diet containing 14,012 mg amino acids and $379 \mathrm{kcal}$ per $100 \mathrm{~g}$ diet. However, each group in the study consumed almost the same amount of calories, which allowed them to gain weight. Therefore, the effect of the orally administered, glutamine-enriched, elemental diet could be determined without the influence of the difference in total nitrogen content and calories. 
Glutamine is an essential nutrient for rapidly dividing cells [12], and has been reported to promote cellular differentiation in the intestine in vitro [13]. Furthermore, glutamine is an important amino acid for maintenance of gutassociated lymphatic tissue and for prevention of bacterial translocation from the gut [14]. The present study showed that serum glutamine levels, mucosal Al-p activity, and BrdUrd labelling index were all significantly higher in the glutamineenriched diet group than in the glutamine-free diet group. The BrdUrd labelling index is an indicator of the regenerative ability of epithelium [11]. Mucosal Al-p is a brush-border enzyme, and its activity is increased by fat feeding [15]. Therefore, an orally administered, glutamine-enriched, elemental diet is suggested to promote the regeneration and differentiation of the intestinal mucosa following massive small bowel resection.

The histological findings in the present study showed that the fat infiltration in the liver was more severe in the glutamine-free diet group than in the glutamineenriched diet group. The mechanism by which glutamine prevents hepatic steatosis has not been established. Helton et al. [6] suggested that the prevention of hepatic steatosis by glutamine may be due to both glucagon-dependent and glucagonindependent mechanisms. However, other studies have demonstrated that enteral infusions of glutamine can decrease peripheral lipolysis [16] and fat uptake by the liver [17] independent of insulin and glucagon. Increased glutamine metabolism by hepatocytes in the periportal region, which cells contain a high level of glutaminase, has been reported to alter lipid uptake and/or metabolism [18].

In summary, oral intake of an elemental glutamine-free diet with hypertonic dextrose resulted in hepatic steatosis in rats following small bowel resection. The addition of glutamine to the elemental diet significantly attenuated hepatic fat accumulation and promoted the regeneration and differentiation of the intestinal mucosa. The significant effect of orally administered glutamine on the histological change in the liver and regeneration of small bowel mucosa illustrates that glutamine is important for the adaptation of the small intestine following massive bowel resection.

\section{REFERENCES}

1. Jeejeebhoy, K.N. (1983): Therapy of the short-gut syndrome. Lancet, 1, 1427-1430.

2. Neptun, E.M. (1965): Respiration and oxidation of various substrates by ileum in vitro. Am. J. Physiol., 209, 509-519.

3. Rombeau, J.L. (1990): A review of the effect of glutamine-enriched diets on experimentally induced enterocolitis. JPEN, 14, 100S-105S.

4. McAnena, O.J., Moore, F.A., Moore, E.E., Jones, T.N., and Parsons, P. (1991): Selective uptake of glutamine in the gastrointestinal tract: Confirmation in a human study. Br. $J$. Surg., 78, 480-482.

5. O'Dwyer, S.T., Smith, R.J., Hwang, T.L., and Wilmore, D.W. (1989): Maintenance of small bowel mucosa with glutamine-enriched parenteral nutrition. JPEN, 13, 579-585.

6. Helton, W.S., Smith, R.J., Rounds, B.S., and Wilmore, D.W. (1990): Glutamine prevents pancreatic atrophy and fatty liver during elemental feeding. J. Surg. Res., 48, 297-303. 
7. Ohashi, H. (1990): Basic characteristics of elemental diet. Dig. Absorp., 13, 90-93 (in Japanese with an English abstract).

8. Fujiwara, M., Ishida, Y., Nimura, M., Toyama, A., and Kinoshita, T. (1987): Postcolumn fluorometric detection system for liquid chromatographic analysis of amino and imino acids using $o$-phthalaldehyde/N-acetyl-L-cysteine reagent. Anal. Chem., 166, 72-78.

9. Lowry, O.H., Rosebrough, N.J., Farr, A.L., and Randall, R.J. (1951): Protein measurement with the folin phenol reagent. J. Biol. Chem., 193, 265-275.

10. Lowry, O.H., Roberts, N.R., Wu, M.L., Hixon, W.S., and Grawford, E.J. (1954): The quantitative histochemistry of brain. II. Enzyme measurements. Biol. Chem., 207, 19-37.

11. Yonemura, Y., Ooyama, S., Sugiyama, K., Kamata, T., Aretxabala, X., Kimura, H., Kosaka, T., Yamaguchi, A., Miwa, K., and Miyazaki, I. (1990): Retrospective analysis of the prognostic significance of DNA ploidy patterns and S-phase fraction in gastric carcinoma. Cancer Res., 50, 509-514.

12. Reitzer, L.J., Wice, B.M., and Kennell, D. (1979): Evidence that glutamine, not sugar, is the major energy source for cultured HeLa cells. J. Biol. Chem., 254, 2669-2676.

13. Beaulieu, J.F., and Calvert, R. (1985): Permissive effect of glutamine on differentiation of fetal mouse small intestine in organ culture. Differentiation, 29, 50-55.

14. Alverdy, J.C. (1990): Effects of glutamine-supplemented diets on immunology of the gut. $J P E N, 14,109 \mathrm{~S}-113 \mathrm{~S}$.

15. Young, G.P., Friedman, S., Yedlin, S.T., and Alpers, D.H. (1981): Effect of fat feeding on intestinal alkaline phosphatase activity in tissue and serum. Am. J. Physiol., 241, G461G468.

16. Dechelotte, P., Darmaun, D., Rongier, M., Hecketsweiler, B., Rigal, O., and Desjeux, J. (1991): Absorption and metabolic effects of enterally administered glutamine in humans. Am. J. Physiol., 260, G677-G682.

17. Cersosimo, E., Williams, P., Hoxworth, B., and Abumrad, N. (1986): Glutamine blocks lipolysis and ketogenesis of fasting. Am. J. Physiol., 250, E248-E252.

18. Li, S., Nussbaum, M.S., McFadden, D.W., Dayl, R., and Fischer, J.E. (1989): Reversal of hepatic steatosis in rats by addition of glucagon to total parenteral nutrition. J. Surg. Res., 46, 557-565. 